\title{
Desain Alat Periksa Mata Fundus Portable Berbasis Rapid Prototyping untuk Mendukung Diagnosa Secara Telemedicine di Indonesia
}

\author{
Fauzziyah Wahyu Aprilia dan Djoko Kuswanto \\ Departemen Desain Produk Industri, Institut Teknologi Sepuluh Nopember (ITS) \\ e-mail: crewol@prodes.its.ac.id
}

\begin{abstract}
Abstrak - Mata merupakan salah satu anggota tubuh yang paling penting sebagai penglihatan manusia. Karena tanpa indera penglihatan, kebebasan, kepercayaan diri, dan produktivitas manusia akan terganggu. Diperlukan adanya pencegahan dini dan pengobatan terhadap penyakit mata dengan melakukan pemeriksaan mata. Salah satunya dengan menggunakan oftalmoskopi atau funduskopi, khususnya funduskopi indirek dengan medan periksa yang lebih luas. Namun Alat tersebut tidak dapat dibawa maupun dipindah dengan mudah, mengingat ukurannya yang cukup besar dan berat. Selain itu, harga jual produk mencapai puluhan hingga ratusan juta rupiah per unit nya. Maka pengembangan produk dimulai dengan pengambilan data primer dan sekunder. Analisis pertama yang dilakukan yaitu pemilihan fitur produk yang akan diaplikasikan pada desain, hingga kebiasaan pengguna untuk mengidentifikasi peluang desain. Lalu dilakukan analisis posisi arm untuk mengetahui posisi yang tepat dalam perancangan produk. Serta studi genggaman tangan untuk mendapatkan rekomendasi desain yang terkait dengan kenyamanan pengguna. Setelah itu, dilakukan pengembangan desain dimulai dari ideasi sketsa, alternatif desain, pengembangan alternatif desain ke dalam beberapa varian desain. Dari varian desain desain tersebut dapat kembali dikembangan menjadi beberapa varian desain final yang lebih fokus, serta dapat dikembangkan lebih lanjut.
\end{abstract}

Kata Kunci-Alat Periksa Mata, Funduskopi, Telemedicine, dan 3D Printing.

\section{PENDAHULUAN}

$\mathrm{M}$ ATA merupakan salah satu panca indera yang penting sebagai penglihatan manusia. Karena tanpa indera penglihatan, maka kebebasan, kepercayaan diri, dan produktivitas manusia akan terganggu. Berdasarkan hasil interview dengan Prof. Dr. Diany Yogiantoro $\operatorname{SpM}(\mathrm{K})$ selaku dokter spesialis mata di Rumah Sakit Siloam Surabaya, bahwa mata merupakan jendela hati, jendela dunia, dan jendela penyakit. Karena melalui pemeriksaan pada mata, penyakit dalam tubuh manusia dapat dideteksi. Seiring dengan bertambahnya usia, mata dan mekanisme kepekaannya makin rentan terhadap kerusakan dan penyakit.

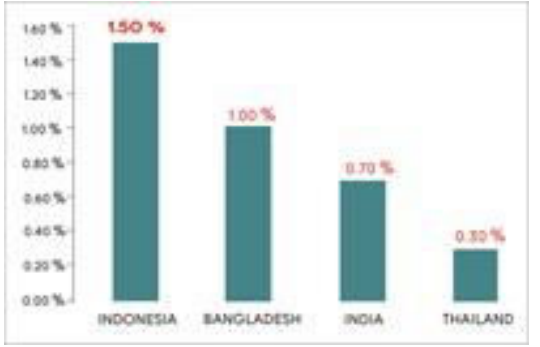

Gambar 1. Gambar bagan presentase kebutaan di Asia Tenggara diolah dari hasil riset Perdami [1].

Berdasarkan data oleh Perdami (Persatuan Dokter Mata Indonesia) diatas menunjukkan bahwa terdapat $1,5 \%$ dari populasi ( 3 juta orang) menderita kebutaan, dimana Indonesia merupakan negara tertinggi dibanding dengan negara Asia Tenggara lainnya. Selain itu, setiap tahun nya terdapat 210.000 orang mengalami kebutaan. Dapat diketahui bahwa kebutaan dan gangguan penglihatan mata masih menjadi masalah kesehatan masyarakat di Indonesia hingga saat ini. Diantara sebab gangguan penglihatan yang masih menjadi masalah kesehatan masyarakat di Indonesia yaitu ketersediaan sarana dan prasana di Indonesia [2]. Tanpa peralatan kesehatan yang memadai, tentu dokter tidak dapat memeriksa, mendiagnosa, serta mengambil tindakan lanjut bagi pasien dengan baik.

Salah satu peralatan kesehatan mata yang penting guna memeriksa bagian retina mata yaitu oftalmoskopi. Oftalmoskopi atau disebut juga funduskopi adalah cara untuk memeriksa bagian dalam bola mata terutama untuk memeriksa arsitektur retina dan diskus optik. Oftalmoskopi terdiri dari dua jenis yaitu, oftalmoskopi direk dan indirek. Adapun perbedaannya terletak pada luas medan periksa. Medan periksa pada oftalmoskopi indirek lebih luas, sehingga kelainan pada mata dapat diketahui lebih detil dan jelas. Sedangkan pada ofalmoskopi direk medan yang diperiksa lebih kecil [3]. Untuk harga produk oftalmoskopi indirek, dibanderol dengan kisaran harga puluhan hingg ratusan juta rupiah. Semua kamera fundus yang ada di pasaran saat ini merupakan produk impor, sehingga harga tersebut belum termasuk dengan biaya pengiriman, pajak, dan biaya tambahan lainnya. Sehingga tidak menutup kemungkinan biaya produk akan semakin mahal. 
Kini oftalmoskopi indirek dengan berbasis Rapid Prototyping yaitu 3D printing tengah dikembangkan. Dengan tidak melupakan fungsi dasar nya, teknologi manufaktur ini pun sudah sering digunakan dalam bidang medis (biomedical) modern. Teknologi Rapid Prototyping dengan metode lapisan memungkinkan pembuatan prototip produk secara langsung [4]. Adapun biaya yang dibutuhkan dalam produksi oftalmoskopi indirek berbasis 3D printing menjadi jauh lebih terjangkau [5]. Oftalmoskopi indirek 3D printing digunakan untuk aktivitas yang tidak hanya berdiam di satu tempat baik dalam maupun luar ruangan. Sehingga dibutuhkan alat yang ringan, mudah dibawa kemanapun (portable), mudah dalam penggunaan dan penyimpanan, serta dapat digunakan di dalam maupun luar ruangan. Oftalmoskopi indirek 3D printing dioperasikan dengan smartphone untuk menghasilkan gambar kondisi mata secara langsung melalui kamera. Dengan terhubungnya produk dengan smartphone, maka akan memudahkan dokter dalam mengirim data atau hasil diagnosa menuju dokter lain/pihak Rumah Sakit/pasien. Teknologi ini biasa disebut dengan Telemedicine, yaitu dengan memanfaatkan jaringan komunikasi seperti multimedia message, chat messenger, atau e-mail.

\section{METODE PENELITIAN}

Dalam proses perancangan penulis menggunakan beberapa metode pengumpulan data, baik data primer maupun sekunder. Dalam pengumpulan data primer, digunakan metode observasi, interview, shadowing, dan usability test. Sedangkan dalam pengumpulan data sekunder didapatkan dari berbagai literatur berupa buku, jurnal, artikel, dan internet.

\section{A. Tahap Pengambilan Data}

Pengambilan data diperoleh dengan beberapa metode yaitu observasi, interview, shadowing, usability test, dan literatur yang terkait dengan penelitian. Adapun untuk data primer tersebut meliputi; interview dengan beberapa dokter spesialis mata; observasi dan shadowing dilakukan di RSAL Dr. Ramelan dan RS Siloam Surabaya dalam beberapa kali pertemuan dengan cara mengamati lingkungan dan aktivitas subjek dalam kurun waktu tertentu atas izin subjek tersebut.; usability test dilaksanakan dengan cara melakukan tes secara langsung kepada target user untuk mendapatkan review lansung dari ahli.

\section{B. Tahap Studi dan Analisis}

Studi dan anlisis dilakukan untuk menentukan kriteria, batasan, dan konsep produk yang akan dirancang, diantaranya yaitu :

1. Analisis pemilihan fitur produk : Untuk menentukan fitur apa saja yang akan diterapkan pada produk yang akan dirancang dengan membandingkan dengan fitur produk kompetitor.

2. Acuan produk : Menggunakan beberapa fitur pada produk lain sebagai acuan untuk diterapkan pada produk yang akan dirancang

3. Studi dan analisis produk open source : Yaitu dengan mengamati dan menganilisis langsung produk open source (eksisting) untuk kemudian dapat dijadikan sebagai acuan dalam pemeberian dimensi pada produk yang akan dirancang.

4. Studi aktivitas : Untuk mengetahui aktivitas dan interaksi taget user, sehingga dapat ditemukan highlight dan peluang desain

5. Studi kebiasaan user : Melalui kebiasaan user dalam mengoperasionalkan produk, khususnya yang terkait dengan produk yang akan dirancang, maka dapat ditemukan peluang desain

Tabel 1.

Kebiasaan Pengguna

\begin{tabular}{lll}
\hline Gambar & $\begin{array}{l}\text { Kebiasaan } \\
\text { Pengguna }\end{array}$ & Potensi Desain \\
\hline & $\begin{array}{l}\text { Dokter secara } \\
\text { manual }\end{array}$ & $\begin{array}{l}\text { Menerapkan } \\
\text { sistem } \\
\text { memaju- }\end{array}$ \\
mundurkan & adjuble pada \\
lensa aspheric \\
dari mata \\
pasien
\end{tabular}

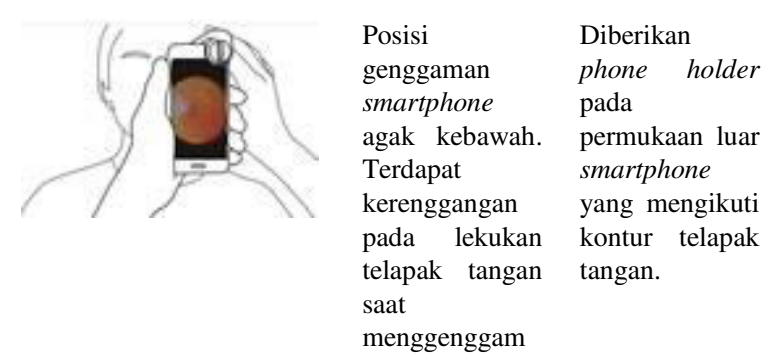

6. Studi fiksasi jarak lensa ke mata : Dengan mengetahui operasional dan fiksasi lensa dapat ditemukan batasan desain dan penerapan dimensi produk yang akan dirancang.

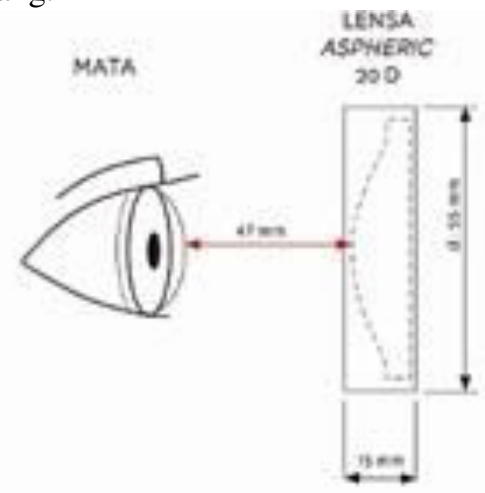

Gambar 2. Fiksasi mata ke lensa.

Jarak lensa aspheric ke mata tergantung dengan tipe lensa nya. Pada gambar diatas merupakan jarak lensa 20D ke mata yaitu $\pm 47 \mathrm{~mm}$. Adapun jarak tersebut tidak dapat dijadikan sebagai patokan, karena kekuatan bola mata tiap orang berbeda-beda.

7. Analisi posisi arm : Dengan visualisasi posisi arm pada produk dapat diketahui rekomendasi posisi arm yang dapat diterapkan dalam perancangan produk 
Tabel 2. Posisi Arm

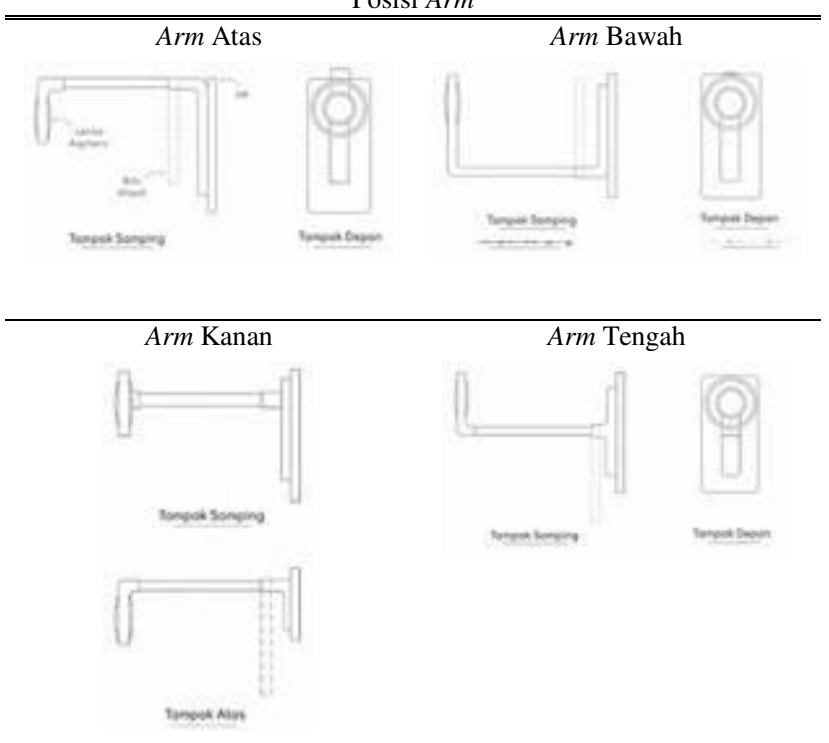

Berdasarkan visualisasi 4 posisi arm berbeda diatas, juga dengan pertimbangan visualisasi ketika produk dilipat, maka didapat hasil akhir yang akan diterapkan pada perancangan yaitu posisi arm atas dan tengah. Adapun pertimbangan dalam pemilihannya yaitu :

a. Arm mudah untuk dilipat

b. Orientasi ketika arm dilipat tetap mudah dalam penyimpanannya

c. Tidak menghalangi genggaman tangan pengguna

d. Efisiensi material

8. Studi Genggaman tangan terhadap smartphone : Dengan mengetahui genggaman tangan dapat diketahui rekomendasi desain yang akan diterapkan pada perancangan produk terkait dengan kenyamanan genggaman dan keamanan smartphone.

\section{HASIL DAN PEMBAHASAN}

A. Sketsa Ideasi

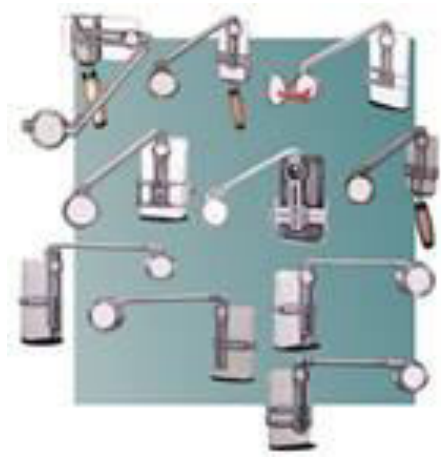

Gambar 3. Sketsa Ideasi.

Alternatif desain dimulai dengan sketsa ideasi awal hingga pembuatan model dengan aplikasi solidworks.

\section{B. Alternatif Desain}

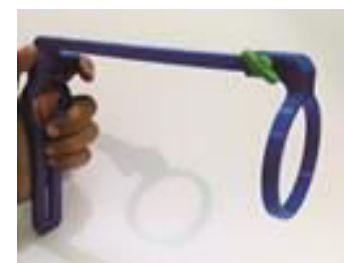

Gambar 4. Alternatif desain 1.

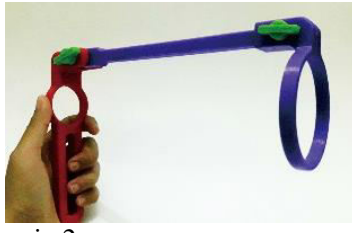

Gambar 5. Alternatif desain 2.

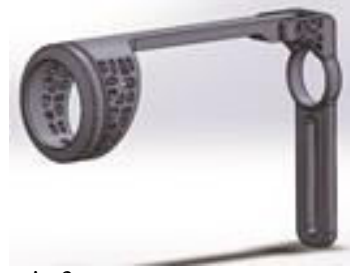

Gambar 6. Alternatif desain 3.

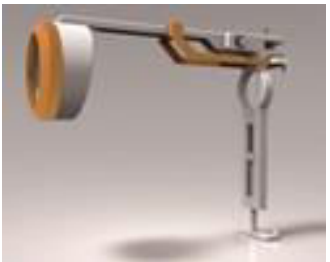

Gambar 7. Alternatif desain 4.

\section{Keterangan :}

Berdasarkan keempat alternatif tersebut, maka alternatif desain 4 dijadikan sebagai desain terpilih yang akan dikembangkan ke dalam beberapa pengembangan desain dengan mengacu pada sutau sistem pada part alternatif desain 4 tersebut.

\section{Simulasi Digital}

Dilakukan simulasi uji stress, displacement, dan strain ketika produk diberikan beban lensa aspheric seberat 200 gr. Simulasi digital menggunakan aplikasi solidworks. Dengan melakukan simulasi dapat diketaui adanya titik kritis dan deformasi produk, sehingga pada pengembangan desain selanjutnya dapat diperbaiki.

\section{Proses Prototyping}

Gambar 8. Proses pencetakan.

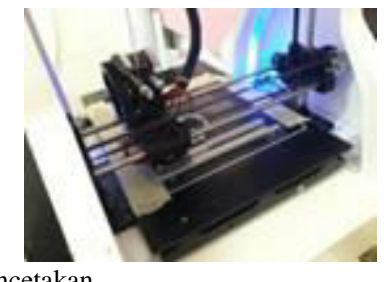

Proses prototyiping menggunakan teknologi 3D printing, dengan menggunakan model CAD tiga dimensi yang disimpan dalam file dengan format STL (Stereo Lithography) [4]. 


\section{E. Pengembangan Desain Alternatif Terpilih}

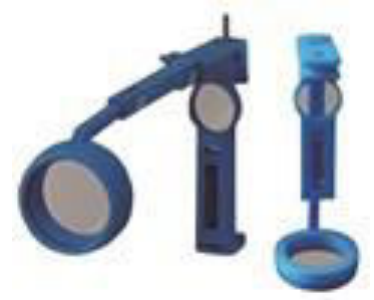

Gambar 9. Pengembangan desain varian 2.

Keterangan :

- Terdapat sistem adjustable pada arm, sehingga part lensa dapat di maju mundurkan pada jarak tertentu

- Sistem penutup lensa berupa ulir, yaitu ketika akan meletakkan lensa aspheric, maka penutup lensa dibuka dahulu dengan cara diputar

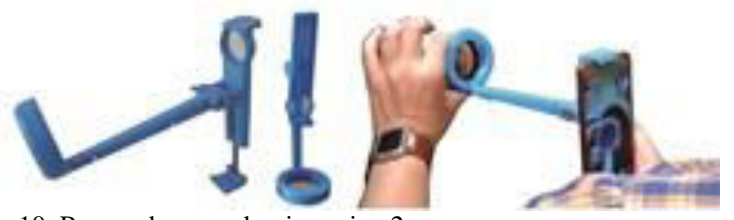

Gambar 10. Pengembangan desain varian 2.

Keterangan :

- Terdapat sistem adjustable pada arm, sehingga part lensa dapat di majumundurkan pada jarak tertentu

- Sistem pengunci/penutup lensa tanpa ulir, yaitu ketika akan meletakkan lensa aspheric, maka penutup lensa dibuka dahulu dengan langsung membuka nya

- Arm berada di tengah dengan pertimbangan struktur yang lebih kuat

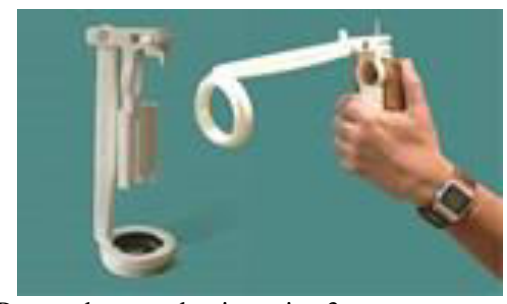

Gambar 11. Pengembangan desain varian 3.

Keterangan :

- Terdapat rail adjustable pada bagian bawahnya sehingga part adjuster dapat digeser ke kanan dan kiri

- Terdapat sistem adjustable pada arm, sehingga part lensa dapat di maju-mundurkan pada jarak tertentu

- Sistem pengunci/penutup lensa tanpa ulir, yaitu ketika akan meletakkan lensa aspheric, maka penutup lensa dibuka dahulu dengan langsung membuka nya

- Phone holder mengitari sisi kanan smartphone, dan berupa rounded edge dengan pertimbangan kontur tangan ketika menggenggam smartphone

\section{F. Usability Test}

Usability testing atau uji coba langsung prototip kepada calon pengguna, yaitu dokter spesialis mata guna mengetahui kekurangan produk dan untuk mendapatkan review produk langsung dari pengguna.

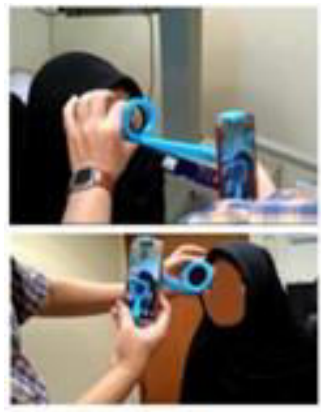

Gambar 12. Usability Testing 1.

Uji coba varian 2 dengan menggunakan lensa, langsung kepada pasien. Dokter menggenggam smartphone menggunakan tangan kanan sembari mengatur fokus dan menekan tombol capture. Sedangkan tangan kiri untuk mengatur jarak lensa dengan pasien.
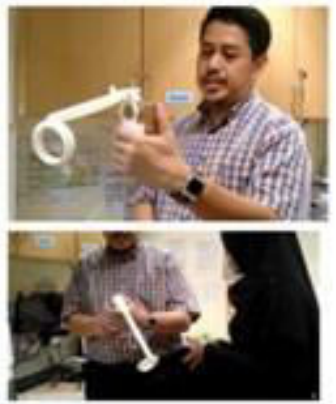

Gambar 13. Usability Testing 2.

Genggaman tangan antara produk dengan smartphone, dokter menyampaikan bahwa jarak kamera smartphone ke lensa perlu diperhatikan agar dapat menghasilkan gambar retina denan jelas.

\section{KONSEP DESAIN}

\section{A. Portable}

Berdasarkan hasil analisa aktivitas, affinity diagram, dan analisa lainnya yang telah dilakukan, adapun konsep desain yang akan diaplikasikan dalam perancanganan yaitu Portable, Less Parts, Less Joining System, Easy to Use, dan Space Saving.

\section{B. Universal}

Adapun maksud dari universal yaitu, produk dapat digunakan oleh semua merek smartphone, dengan posisi kamera dan flash yang berbeda-beda pada tiap tipe nya. Terdapat adjustable berupa mur dan baut pada bagian phone holder sehingga dapat diatur sesuai dengan posisi kamera.

\section{Easy to Use}

Easy to use atau mudah dalam pengoperasionalan. Pengguna dapat mengoperasioanalkan produk dengan mudah, aman, nyaman, dan mengurangi keletihan. Penggunaan alat perkakas seperti obeng pun tidak digunakan dalam penguncian produk karena selain kurang praktis, juga dapat menimbulkan 
keletihan bagi pengguna. Penggunaan produk pun lebih mudah, yaitu pengguna cukup menyematkan lensa optik pada penutup/penjepit lensa dan produk pun siap digunakan pada pasien.

\section{Space Saving}

Space saving atau menghemat penggunaan ruang penyimpanan produk. Ketika produk sedang tidak digunakan, pengguna dapat menyimpan produk pada sebuah kantung/tas kecil agar produk tetap aman dan terlindungi. Maka agar tidak menghabiskan banyak ruang, produk dapat dilipat agar lebih ramping dan praktis.

\section{E. Less Joining}

Less joining atau meminimalisir penggunaan aksesoris untuk menggabungkan tiap part. Dengan menggunakan aksesoris yang lebih sedikit, maka proses pemasangan maupun pembongkaran produk dapat leboh efisien, efektif, dan tidak menimbulkan kebingungan pada pengguna.

\section{KESIMPULAN/RINGKASAN}

Berikut merupakan kesimpulan dari perancangan alat periksa mata fundus potable berbasi rapid prototyping. Kesimpulan didapatkan setelah dihasilkan beberapa prototype dan dilakukan usability testing kepada dokter spesialis mata di RS Siloam Surabaya serta dilakukan interview kepada beberapa dokter spesialis mata. Adapun kesimpulannya sebagai berikut :

1. Desain alat periksa mata dapat mencapai tujuan perancangan yang telah dijelaskan pada $\mathrm{BAB} 1$, sebagai berikut :

a. Alat periksa kesehatan mata dapat diterapkan pada semua lembaga kesehatan seperti Rumah Sakit, Klinik Mata, serta Puskesmas, maupun kegiatan sosial kesehatan lainnya

b. Harga jual produk terjangkau dengan proses produksi berbasis Rapid Prototyping, yaitu 3D Printing

c. Produk dapat digunakan oleh semua merek smartphone, namun hanya untuk ukuran tertentu, yaitu smartphone dengan ukuran layar 5,0" $-6,0$ ” d. Produk apat disematkan lensa aspheric dengan menyesuaikan dimensi. Serta aman ketika produk disematkan lensa aspheric dengan beban sebesar \pm 200 gr, dengan melakukan simulasi digital menggunakan aplikasi solidworks

e. Produk aman digunakan dalam bidang alat kesehatan medis dengan menggunakan teknologi 3D printing

2. Adapun temuan atau pengembangan fitur-fitur baru yang diterapkan pada produk yang mengacu pada produk lain untuk memberikan kemudahan operasional, efektifitas dan efisiensi waktu dalam perakitan maupun ketika produk digunakan oleh target user, sebagai berikut :

a. Penutup lensa aspheric berupa ulir, sehingga lebih aman dan mudah dalam penempatan lensa aspheric

b. Adjuster sistem geser terhadap phone holder, sehingga bukan smartphone yang bergeser untuk menyesuaikan, namun adjuster yang digeser untuk menyesuaikan dengan lensa aspheric

c. Sistem lipat pada bagian arm, sehingga apabila produk sedang tidak digunakan, dapat disimpan pada sebuah wadah atau pouch dengan tidak menghabiskan banyak ruang dalam penyimpanannya

d. Sistem adjustbale pada arm, sehingga jarak antara lensa aspheric dengan kamera smartphone dapat diatur secara fleksibel (jarak tidak fix)

e. Genggaman phone holder rounded, yang menyesuaikan dengan kontur telapak tangan yang curvy, sehingga genggaman dapat lebih nyaman

\section{DAFTAR PUSTAKA}

[1] Persatuan Dokter Mata Indonesia, "Vision 2020 di Indonesia," Jakarta, 2017.

[2] Kementerian Kesehatan RI, "Situasi Gangguan Penglihatan dan Kebutaan," Jakarta, 2014.

[3] Dr. Hartono, Oftalmoskopi, dasar dan klinis. Yogyakarta: Pustaka Cendekia Press, 2007.

[4] A. Kholil, Rapid Prototyping. Depok: UI Press, 2008.

[5] S. C. Hong, 3D Printing and Ophthalmology for the Community. Gisborne, 2015. 